\title{
A Survey of Knowledge and Practices in Generic Prescribing Among Doctors in Kurunegala District, Sri Lanka
}

\author{
A.P.MADURAGODA ${ }^{1}$, S.M.N.S.M.MALLAWARACHCHI ${ }^{2}$
}

\begin{tabular}{|c|c|}
\hline & ABSTRACT \\
\hline $\begin{array}{r}\text { Corresponding Author } \\
\text { S.M.N.S.M.Mallawarachchi } \\
\text { Doi } \\
\text { https://10.48121/jihsam.897336 } \\
\text { Received } \\
15.02 .2021 \\
\text { Accepted } \\
\text { 01.10.2021 } \\
\text { Published Online } \\
27.10 .2021 \\
\text { Key Words } \\
\text { Generic Prescribing } \\
\text { Knowledge } \\
\text { Practices } \\
\text { Doctors } \\
\text { Sri Lanka }\end{array}$ & $\begin{array}{l}\text { Generic prescribing is promoted by most governments } \\
\text { and insurers as a measure of reducing health care cost. } \\
\text { Doctors are key player's health care provision and } \\
\text { powerful deciders in drug market. The practice of doctors } \\
\text { in prescribing is critical in determining both clinical and } \\
\text { economic efficiency and effectiveness of a health system. } \\
\text { The study aimed to assess the doctors' knowledge and } \\
\text { practices in generic prescribing. The study was } \\
\text { questionnaire based and conducted in Kurunegala district } \\
\text { in Sri Lanka with the participation of government doctors. } \\
\text { It was revealed that most doctors were engaged in generic } \\
\text { prescribing and they had a satisfactory knowledge } \\
\text { regarding the concept. Practice of generic prescribing } \\
\text { among doctors was not significantly associated with their } \\
\text { work experience, gender, engagement in private practice } \\
\text { or post graduate qualifications. It was depicted that the } \\
\text { promotional visits by representatives of pharmaceutical } \\
\text { companies mainly focused at doctors who did part time } \\
\text { private practice. Yet it was claimed that most doctors did } \\
\text { not consider brand name when purchasing drugs for their } \\
\text { practices. }\end{array}$ \\
\hline
\end{tabular}

1 Dr., Ministry of Health, Sri Lanka. amilamadu@ @mail.com / https://orcid.org/0000-0001-6361-4112

${ }^{2}$ Dr., Ministry of Health, Sri Lanka. Navodasandamali79@ gmail.com / https://orcid.org/0000-0001-5323-3367 


\section{INTRODUCTION}

State health sector is the key provider in health care in Sri Lanka through which health services are provided free at the point of delivery. In addition, private sector provides care charging user fees. Doctors employed in the state health sector are allowed to carry out private practice after hospital duty hours (De Silva, 2017).

Drugs are a vital and expensive component in provision of healthcare. Ensuring an adequate supply of safe and effective drugs of acceptable quality is a priority in a country's health system. Rational prescribing is certainly a primary and essential step in ensuring rational use of drugs. Inappropriate prescribing is potentially harmful for both the individual and society (Carthy et al., 2000). Over the years, pharmaceutical expenditure has risen globally which has been a reason for concerns among policymakers to consider measures to guarantee the sustainability of health care systems. Awareness of factors influencing physician behavior in prescribing could be useful in policy development and thereby ensuring clinical and economic effectiveness and efficiency (Theodorou et al., 2009).

Although drugs are provided to patients free of charge in government hospitals in Sri Lanka, patients would need to purchase some from private pharmacies spending out of pocket, which may not be available in the hospital. Drugs are available in the market in generic and branded versions. A generic medicine is a pharmaceutical product usually intended to be interchangeable with the originator brand product, manufactured without a license from the originator manufacturer and marketed after the expiry of patent or other exclusivity rights (World Health Organization, 2016; "WHO Definitions of Generics," 2012). Generics are equal to the relevant innovator drug/ brand name counterpart in terms of bioequivalence, dose, dosage form and the composition of active ingredients.

Generic medicines are marketed either under a non-proprietary name rather than under a proprietary or brand name and can be available in the market in parallel with the originator brand product. As generic medications are less expensive than brand-name counterparts, many governments and private insurers have promoted or mandated the use of generics (Keenum et al., 2012). With the implementation of the National Medicines Regulatory Authority Act of Sri Lanka - 2015, the prescribers were encouraged to use the generic names of drugs with an option of writing the brand alongside (National Medicines Regulatory Authority Act 2015. (No.5), 2015).

Though generic and brand-name medications produce similar clinical outcomes, there are differences in shape, colour, taste, and name that can lead to patient confusion and nonpersistent use of medications (McCormack \& Chmelicek, 2014). The global market of pharmaceutics is vast, ever growing, and competitive and the huge significance of pharmaceutical companies in a country's economy is very much evident. However, unlike the traditional buying decision process in non-health markets, the agents, gatekeepers and deciders in the prescription medicine market are doctors (Sharifnia et al., 2018). The influence of physician- pharmaceutical industry interactions in prescribing and professional behavior have been questioned in world literature (Wazana, 2000) which is starkly contrasted in the doctors' choice of generic vs branded medications.

The prescribing patterns and behavior of doctors are strongly related to their knowledge in which generic prescribing represent a considerable segment. In a developing country like Sri Lanka where population could be benefitted with availability of low-cost quality drugs, enhanced by generic prescribing, can be promoted, and ensured with wellchosen strategies. Selection and implementation of such is supported and guided by understanding of health professionals' knowledge and practices generated by scientific researches like the current study.

Current study intended to assess the knowledge and practices in generic prescribing among doctors employed in state health sector in the Kurunegala district, Sri Lanka.

\section{MATERIALS AND METHODS}

The study was descriptive and cross-sectional. Out of the doctors employed in state hospitals in Kurunegala district 274 were selected randomly for the study.

A self-administered questionnaire was used to assess the knowledge and practices in generic prescribing among doctors. The questionnaire had nine questions which checked the knowledge of the participants in selected aspects regarding generic medicines. The questions covered the following aspects.

$\checkmark$ Comparison of chemical entity in generic medicines and innovator drugs / brand name medicines

$\checkmark$ Whether generic medicines are manufactured after the patent expiry of originator/innovator medicine.

$\checkmark$ Whether generic medicines are not available in developed countries 
Comparison of safety of generic medicines vs. brand name medicines

$\checkmark$ Whether generic medicines are therapeutically equivalent to brand name medicines

$\checkmark$ Whether brand name medicines produce less side effects than generic medicines

$\checkmark$ Whether brand name medicines are required to meet higher safety standards than generic medicine

$\checkmark$ Whether generic medicines must be in the same dosage form (such as tablet, capsule) as brand name medicines

$\checkmark$ Whether only the branded drugs need to be registered with drug regulatory authority in Sri Lanka

The accuracy of answer to each was assessed to calculate the cumulative percentage of total correct responses. Both "do not know" and blank responses were considered as incorrect. If the cumulative percentage of total correct responses of a participant for knowledge related questions were equal or more than $50 \%$ it was considered as satisfactory. The practice of prescribing among doctors was assessed through the questionnaire itself with a Likert scale with 'Always' 'Often' 'Sometimes' 'Occasionally' and 'Never' responses. During analysis, the 'Always' and 'Often' were counted for common and the others for less common practice.

The questionnaires along with the information sheet and the consent form were posted to the randomly selected doctors together with an envelope addressed to principal investigator to mail the filled questionnaire back. The mobile number of the principal investigator was noted in the information sheet so that those who had any concerns could clarify same if any.

Data was analyzed using SSPS software, Pearson's Chi-Squared test was used to find the associations between variables. Due administrative approval was obtained from relevant authorities.

\section{RESULTS}

Among the total questionnaires returned, only 238 were eligible for the study as the others were filled incompletely.

Among the doctors, $55.5 \%$ did not know that the chemical entity in generic medicines and innovator / brand name medicines were similar. Majority of $79.4 \%$ were not aware of the fact that the generic medicines were manufactured after the patent expiry of originator/innovator medicines. Although $77.7 \%$ of doctors knew generics were as safe as innovator drugs, $51.7 \%$ had responded contradictorily when questioned about the therapeutic equivalence of generic and innovator drugs. Among them, $43.3 \%$ believed branded drugs could give rise to less side effects than their generic counterparts and another $45 \%$ were under the false impression that the branded medicines need to go through higher safety requirements than the generic drugs. A majority $76.9 \%$ knew correctly that registration requirements for generics were like those of branded drugs.

Of the doctors, $64.3 \%$ depicted a satisfactory overall knowledge regarding generic prescribing.

It was noted that $89.8 \%$ doctors claimed that they commonly used generic prescribing in clinical documentation.

The relationship between the practice of generic prescribing with the parameters of gender, service experience, post graduate qualifications and engagement in part time private practice was tested but none showed a statistically significant association (Table 1).

Table 1. Association between selected sociodemographic characteristics of doctors and practice of generic prescribing

\begin{tabular}{|c|c|c|c|c|c|}
\hline Attribute & & Commonly used & $\begin{array}{l}\text { Less commonly } \\
\text { used }\end{array}$ & Total & $\begin{array}{l}\text { Statistical } \\
\text { analysis }\end{array}$ \\
\hline \multirow{2}{*}{ Gender } & Female & $75(89.29 \%)$ & $9(10.71 \%)$ & 84 & \multirow{2}{*}{$\begin{array}{r}\chi^{2}=0.36 \\
\text { df }=1 \\
P=0.850\end{array}$} \\
\hline & Male & $136(90.07 \%)$ & $15(9.93 \%)$ & 151 & \\
\hline \multirow{2}{*}{ Experience } & $<10$ years of service & $161(89.94 \%)$ & $18(10.06 \%)$ & 179 & \multirow{2}{*}{$\begin{array}{r}\chi^{2}=0.020 \\
d f=1 \\
P=0.887\end{array}$} \\
\hline & $>10$ years of service & $50(89.29 \%)$ & $6(10.71 \%)$ & 56 & \\
\hline \multirow{2}{*}{$\begin{array}{l}\text { Postgraduate } \\
\text { qualifications }\end{array}$} & Yes & $38(88.37 \%)$ & $5(11.63 \%)$ & 43 & \multirow{2}{*}{$\begin{array}{r}\chi^{2}=0.115 \\
d f=1 \\
P=0.735\end{array}$} \\
\hline & No & $173(90.10 \%)$ & $19(9.9 \%)$ & 192 & \\
\hline \multirow{2}{*}{$\begin{array}{l}\text { Private } \\
\text { practice }\end{array}$} & Not engaged & $131(91.61 \%)$ & $12(8.39 \%)$ & 143 & \multirow{2}{*}{$\begin{array}{r}\chi^{2}=1.321 \\
d f=1 \\
P=0.250\end{array}$} \\
\hline & Engaged & $80(86.96 \%)$ & $12(13.04 \%)$ & 92 & \\
\hline
\end{tabular}


Regarding prescriptions written for out of pocket purchases by patients, the factors most considered by doctors were, availability of the drug, generic name and price. Only $28 \%$ of doctors considered brand name in prescribing.

The association between practice and knowledge of doctors on generic prescribing was found to be statistically significant $\left(\chi^{2}=12.232, \mathrm{df}=1, \mathrm{P}=0.001\right)$.
Among the sources the doctors relied upon to get drug information, the most popular choice was British National Formulary and the least was drug representatives (Table 2).

Table 2. Sources of information the doctors used to obtain information on drugs

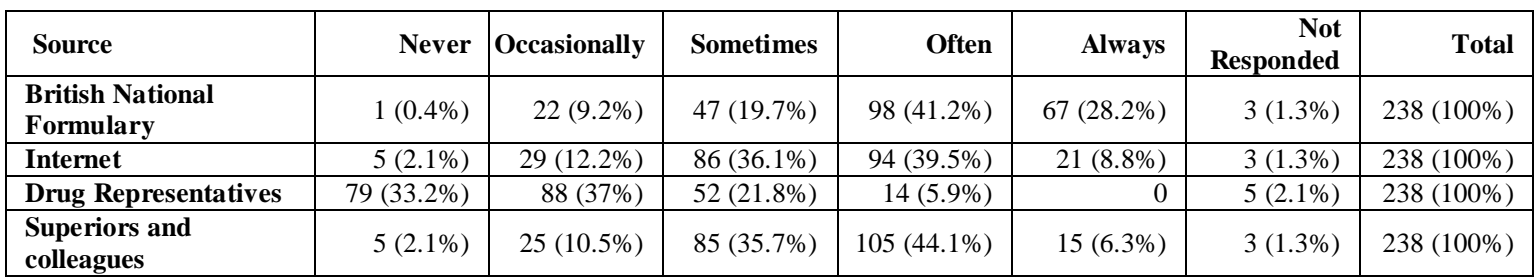

It was revealed that among generic name, brand name, price and availability, the least considered factor by doctors when purchasing medicines for private practices was the brand name (Table 3 ).

Table 3. Factors considered by doctors when purchasing drugs for private practices

\begin{tabular}{|l|r|r|r|r|r|r|r|}
\hline & Never & Occasionally & Sometimes & Often & Always & $\begin{array}{r}\text { Not } \\
\text { Responded }\end{array}$ & Total \\
\hline Generic Name & $2(2 \%)$ & $11(12 \%)$ & $29(32 \%)$ & $46(50 \%)$ & $3(3 \%)$ & $1(1 \%)$ & $92(100 \%)$ \\
\hline Brand Name & $1(1 \%)$ & $18(20 \%)$ & $45(49 \%)$ & $23(25 \%)$ & $3(3 \%)$ & $2(2 \%)$ & $92(100 \%)$ \\
\hline Price & $2(2 \%)$ & $7(7.8 \%)$ & $19(21.2 \%)$ & $49(53 \%)$ & $14(15 \%)$ & $1(1 \%)$ & $92(100 \%)$ \\
\hline Availability & 0 & $3(3 \%)$ & $20(22 \%)$ & $42(46 \%)$ & $26(28 \%)$ & $1(1 \%)$ & $92(100 \%)$ \\
\hline
\end{tabular}

\section{DIS CUSSION}

It was found that among the doctors who were engaged in part-time private practice $91.30 \%$ were visited by representatives of drug companies, whereas among the other doctors only $37.41 \%$ were visited by them. there is a statistically significant association between being visited by drug companies' representatives and the fact whether the doctor was engaged in Private practice $\left(\chi^{2}=66.411\right.$, df $=1, \mathrm{P}=$ $0.001)$.

Generic drug use has been widely recognized to reduce patients' out-of-pocket expenditure and payer costs (Gagne et al., 2014). In general, international studies have shown that important drug-related considerations in prescribing decisions of doctors included efficacy, safety, administration, and cost (Schumock et al., 2004).

Generic substitution of brand prescriptions is an accepted practice in many countries. (Banahan, 1997) Although generic prescribing seemed not be a universally accepted practice among doctors who participated in the current study a majority $(89.8 \%)$ of them claimed to practice it.

In this study, it was observed that $55.5 \%$ did not know that the chemical entity in generic medicines and innovator / brand name medicines were similar while $51.7 \%$ did not believe the therapeutic equivalence of generic and innovator drugs. This finding is rather discouraging since public faith in generic formulations too is not universal. Although wider gaps were recognized when analyzing each component of knowledge, altogether $64.3 \%$ doctors had a satisfactory overall knowledge regarding the concept which was better than the findings of similar studies in the South Asian region (Kembhavi et al., n.d.; Jamshed et al., 2012).

Majority of doctors in the present study (89.8\%) reported that they commonly practiced generic prescribing in clinical documentations, where a survey published in 2011 revealed that over $75 \%$ prescriptions were written in generic names (Menik et al., 2011). Still, the pharmacists having the possibility of brand substitution of prescribed drugs could have played a considerable role in the outcome of pattern of drug consumption and sales.

Although it was indicated that doctors were aware of the role of generic drugs in the improvement of universal access to drugs, they had different views in quality of generic drugs. It could be attributed to the inadequacy of strong and reliable public control routines for drugs with better bioequivalence requirements. 
The recognized scholarly knowledge base has been highlighted as one of the sources used by clinicians to gather information on drugs among other options such as face- to- face communication, hard copy and telephone calls which were still prevailing in the clinical setting (Davies, 2007). The current study depicted that doctors mostly relied upon British National Formulary and less depended on drug representatives. In contrast, commercial sources of information have been recognized to influence general practitioners' prescribing behavior than scientific sources, in under developed and developing countries (Vancelik et al., 2007).

The fact that the visits by representatives of pharmaceutical companies were significantly associated with doctors' engagement in private practice could be a proxy indicator of market influences in prescribing behavior. The pharmaceutical industry had spent nearly $\$ 30$ billion dollars in 2005 in United States on marketing and promotion, of which $84 \%$ had been diverted toward physician detailing and free samples, with less devoted to professional and direct-to-consumer advertising (Donohue et al., 2007; Rosenthal et al., 2002). Although the current study revealed that the influence of brand names did not play a major role in prescribing and purchasing decisions of doctors, the possible guilt of accepting if there were any, because of knowledge in benefits in generic prescribing may have had a masking effect on the real facts which cannot be denied. The picture generated by selfreporting may not completely agree with the real-life practice which is a limitation of the current study as well, which could have been remedied by an audit of prescription notes. The influence of patient's socioeconomic status and the choice of patients to opt for branded medicines, upon the practice of generic prescribing of doctors was not captured by the current study which is another weakness noted. Further research is warranted to assess the impact of patients' factors affecting the practice of generic prescribing.

\section{CONCLUSIONS}

Although the knowledge among doctors regarding generic prescribing had several gaps, majority of doctors had a satisfactory understanding. The knowledge and practice of generic prescribing among doctors depicted a significant association. Mostly the doctors relied for drug information on recognized

\section{Acknowledgments:}

The authors thank all the participants and reviewers of the study.

\section{Conflict of Interest:}

The authors have no conflicting interests regarding the research. scholarly sources. Most doctors claimed that they did not consider brand name as a priority for drug purchasing decisions. But efforts of branded drug promotions through agents' visits were mostly targeted at doctors who were engaged in private practice.

\section{Ethical Approval:}

Ethical approval was granted from the Ethical Review Committee of the Medical Faculty, University of Colombo under reference number EC - 15-043.

\section{Funding:}

The project was self-funded by the authors.

\section{REFERENCES}

1. Banahan, B. F. (1997). A Physician Survey on Generic Drugs and Substitution of Critical Dose Medications. Archives of Internal Medicine, 157(18), 2080. https://doi.org/10.1001/archinte.1997.00440390066010

2. Carthy, P., Harvey, I., Brawn, R., \& Watkins, C. (2000). A study of factors associated with cost and variation in prescribing among GPs. Family Practice, 17(1), 36-41. https://doi.org/10.1093/fampra/17.1.36

3. Davies, K. (2007). The information-seeking behaviour of doctors: A review of the evidence. Health Information and

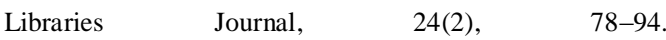
https://doi.org/10.1111/j.1471-1842.2007.00713.x

4. De Silva, D. (2017). How many doctors should we train for Sri Lanka? System dynamics modelling of training needs. Ceylon Medical Journal, 62(4)

5. Donohue, J. M., Cevasco, M., \& Rosenthal, M. B. (2007). A Decade of Direct-to-Consumer Advertising of Prescription Drugs. New England Journal of Medicine, 357(7), 673-681. https://doi.org/10.1056/NEJMsa070502

6. Gagne, J. J., Choudhry, N. K., Kesselheim, A. S., Polinski, J. M., Hutchins, D., Matlin, O. S., Brennan, T. A., Avorn, J., \& Shrank, W. H. (2014). Comparative Effectiveness of Generic and Brand-Name Statins on Patient Outcomes: A
Cohort Study. Annals of Internal Medicine, 161(6), 400. https://doi.org/10.7326/M13-2942

7. Jamshed, S. Q., Ibrahim, M. I. M., Hassali, M. A. A., Masood, I., Low, B. Y., Shafie, A. A., \& Babar, Z.-U.-D. (2012). Perception and attitude of general practitioners regarding generic medicines in Karachi, Pakistan: A questionnaire based study. Southern Med Review, 5(1), 22-30.

8. Keenum, A. J., DeVoe, J. E., Chisolm, D. J., \& Wallace, L. S. (2012). Generic medications for you, but brand-name medications for me. Research in Social and Administrative Pharmacy, $\quad 8(6), \quad$ 574-578 https://doi.org/10.1016/j.sapharm.2011.12.004

9. Kembhavi, R. S., Shinde, R. R., Hagawane, T., Jadhav, R. A., Khairnar, R. R., \& Darade, B. D. (n.d.). Cross Sectional, Observational Study to Assess Prescription Practices of Physicians with Respect to Use of Generic Medicines. International Journal of Pharmaceutical Sciences Review and Research, 25(1), 90-96.

10. McCormack, J., \& Chmelicek, J. T. (2014). Generic versus brand name: The other drug war. Canadian Family Physician, 60(10), 911.

11. Menik, H., Isuru, A., \& Sewwandi, S. (2011). A survey: Precepts and practices in drug use indicators at government 
healthcare facilities: A hospital-based prospective analysis. Journal of Pharmacy and Bioallied Sciences, 3(1), 165. https://doi.org/10.4103/0975-7406.76502

12. National Medicines Regulatory Authority Act 2015. (No.5). (2015). Government Publications Bureau.

13. Rosenthal, M. B., Berndt, E. R., Donohue, J. M., Frank, R G., \& Epstein, A. M. (2002). Promotion of Prescription Drugs to Consumers. New England Journal of Medicine, 346(7), 498-505. https://doi.org/10.1056/NEJMsa012075

14. Schumock, G. T., Walton, S. M., Park, H. Y., Nutescu, E. A., Blackburn, J. C., Finley, J. M., \& Lewis, R. K. (2004). Factors that Influence Prescribing Decisions. Annals of Pharmacotherapy, 38(4), 557-562. https://doi.org/10.1345/aph.1D390

15. Sharifnia, S. H. A., Mohammadzadeh, M., Arzani, G., Salamzadeh, J., Abolfazli, S. A., Zali, A., \& Khoshdel, A. R. (2018). Main Factors Affecting Physicians' Prescribing Decisions: The Iranian Experience. Iranian Journal of Pharmaceutical Research: IJPR, 17(3), 1105-1115.
16. Theodorou, M., Tsiantou, V., Pavlakis, A., Maniadakis, N., Fragoulakis, V., Pavi, E., \& Kyriopoulos, J. (2009). Factors influencing prescribing behaviour of physicians in Greece and Cyprus: Results from a questionnaire based survey. BMC Health Services Research, 9(1), 150. https://doi.org/10.1186/1472-6963-9-150

17. Vancelik, S., Beyhun, N. E., Acemoglu, H., \& Calikoglu, O. (2007). Impact of pharmaceutical promotion on prescribing decisions of general practitioners in Eastern

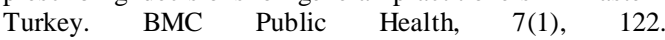
https://doi.org/10.1186/1471-2458-7-122

18. Wazana, A. (2000). Physicians and the Pharmaceutical Industry: Is a Gift Ever Just a Gift? JAMA, 283(3), 373. https://doi.org/10.1001/jama.283.3.373

19. WHO definitions of generics. (2012). Generics and Biosimilars Inititative http://gabionline.net/Generics/General/WHO-definitionsof-generics

20. World Health Organization. (2016). WHO Drug Information-Generic 